\title{
ARTIGOS
}

\section{MANDA NUDES: \\ OS CRUSH GAYS NOS APLICATIVOS FAST FODA DE RELACIONAMENTOS}

\author{
Damião Rocha ${ }^{1}$ \\ Marcos Irondes Coelho ${ }^{2}$
}

Resumo: Com classificação do grau de pegação e com maior chance de sexo, os aplicativos estão se multiplicando e bombando na rede social online. Um desses aplicativos é apresentado com chamada do tipo: se você é um garoto à procura de garotos, esse é seu aplicativo. Com ele você pode ver outras pessoas perto de você e, se eles gostam de garotos, de garotos e garotas ou só querem saber como funciona a coisa toda. O texto resulta das pesquisas que vimos fazendo no Programa de Pós-Graduação em Educação da Universidade Federal do Tocantins (PPGE/UFT), nos últimos cinco anos e retrata as interações das pessoas LGBTQI+ nas redes online, comunidades virtuais ou nos aplicativos. É uma pesquisa qualitativa, de cunho descritivo e analítico, na perspectiva da Netnopesquisa. Dentre outros aspectos o aplicativo mostra a quantos metros de distância cada pessoa está de você e tem a opção de chat imediato e envio de fotos. E como o aplicativo não é integrado necessariamente ao Facebook ou outra rede social, você pode garantir seu anonimato. O que estes aplicativos promovem de interações e curtições são as questões importantes para pensarmos a sociabilidade gay na rede mundial de computadores e o crush como paixão subida, rápida e efêmera.

Palavras-chave: Aplicativos; Sociabilidade de pessoas LGBTQI+; Interações e curtições.

\section{Introdução}

Vivemos em redes sejam elas online ou offline e com a internet as interações ultrapassaram o mundo físico e inundaram o ciberespaço. Com as redes sociais digitais,

\footnotetext{
${ }^{1}$ Doutor em Educação pela UFBA, mestre em educação pela UFG. Professor Adjunto do PPGE/UFT. Líder de grupo de pesquisa sobre currículo, com ênfase em currículo e diversidade sexual e de gênero. Email: damiao@uft.edu.br

${ }^{2}$ Mestre em Educação pela UFT, pesquisa sobre diversidade sexual e de gênero. Professor do sistema estadual de educação do Tocantins. E-mail: marcos.irondes@gmail.com
}

Vol. 01, N. 04, Out. - Dez., 2018 - www.revistas.unilab.edu.br/index.php/rebeh 
com capacidade de registrar e salvar em nuvem tudo que é veiculado por seus usuários, em forma de textos, imagens, vídeos, áudios, etc., sem perigo de serem perdidas de suas memórias, passamos a viver conectados numa grande teia digital. Essa condição propiciou as pessoas Lésbicas, Gays, Bissexuais, Transexuais, Travestis, Transgêneros, Queer, Intersex e mais (LGBTQI+) uma certa naturalização de suas práticas de pegação e deu maior visibilidade, no sigilo, às suas curtições.

A discussão deste tema surge da seguinte questão: os aplicativos proporcionaram maior possibilidade de pegação das pessoas LGBTQI+ por conta do "sigilo" e da possibilidade facilitada de "bloqueio" (apagar, desfazer, remover)? Nosso ensaio trata da investigação na internet e nos aplicativos para observar os formatos de paquera, pegação, flert e encontros sexuais agendados.

Por outro lado, queremos entender se o acesso aos aplicativos proporcionaram maior visibilidade, "aceitabilidade" ou quais mudanças provocaram nas pessoas LGBTQI+. É um trabalho com a Netnopesquisa que se inscreve sob a rubrica da etnografia ou Virtual Ethnography como sugere Christine Hine (2004), uma investigação que constrói seus dados ou obtém suas fontes da internet, com acesso a bases, sites, de informações digitais.

\section{Viver e se pegar na rede online}

As pessoas são de relações, estabelecem relações entre si. Para Vermelho et al. (2014, p. 183) “o termo 'rede social' tornou-se sinônimo de tecnologia da informação e comunicação; seu uso transcorreu áreas e destruiu fronteiras sendo apropriado, hoje, por muitos atores sociais". Desta forma para uma melhor compreensão do significado de redes sociais, entende-se que é uma estrutura social que agrega pessoas ou organizações, conectadas por um ou vários tipos de relações, onde valores e objetivos comuns são compartilhados. Uma das fundamentais características na definição das redes é a sua abertura, possibilitando relacionamentos horizontais e não hierárquicos entre os participantes.

Na definição de Franco (2012, p. 117) redes sociais são como "um processo de socialização, algum tipo de interação coletiva e social, presencial ou virtual, que pressupõe a partilha de informações, conhecimentos, desejos e interesses”.

Vol. 01, N. 04, Out. - Dez., 2018 - www.revistas.unilab.edu.br/index.php/rebeh 
Lorenzo (2013, p. 20) escreve que a "rede social é uma das formas de representação dos relacionamentos afetivos ou profissionais dos seres entre si, em forma de rede ou comunidade. Ela pode ser responsável pelo compartilhamento de ideias, informações e interesses". Esse mesmo autor ressalta, ainda, que as redes sociais no uso da internet, constituem relações interpessoais mediadas por computadores, isso ocorre por meio da interação social na busca da comunicação.

Ainda de acordo com Lorenzo (2013) as redes sociais possibilitam a ampliação das conexões que já dispomos, para além dos nossos relacionamentos presenciais, uma vez que por meio delas é possível saber quem são os amigos de nossos amigos e quais amigos temos em comum, tudo isso torna nossas redes sociais digitais mais amplas e diversas, especialmente se compararmos com nossas redes presenciais.

Na definição de Christakis e Fowler (2010, p. 9) "rede social é um conjunto organizado de pessoas que consiste em dois tipos de elementos: seres humanos e as conexões entre eles". Tais conexões surgem pelos mais variados motivos, por uma necessidade do trabalho, pela busca por relacionamentos afetivos, ou por pura diversão, etc.

A partir das contribuições dos autores é possível inferir que rede social é uma estrutura social composta de relações afetivas ou profissionais de pessoas ou organizações que se conectam entre si. Neste processo as relações sociais são potencializadas contribuindo para a visibilidade nas redes, das diversas culturas e dos diversos sujeitos.

Nesse sentido Louro (2016) escreve que os sujeitos, conectados pela internet, passam a estabelecer relações amorosas que não levam em consideração as dimensões de espaço-tempo-gênero-sexualidade num jogo de múltiplas identidades, de anonimato e de perfis fakes. É certo que pelas possiblidades da internet as práticas sexuais virtuais têm tomado o lugar ou complementado as práticas do face a face. Ainda de acordo com a autora esse movimento tem provocado, especialmente nos adolescentes a experimentação cada vez mais precoce de relacionamentos afetivos e sexuais estáveis com pessoas do mesmo sexo, construindo novos arranjos familiares.

\section{Pegação: tc, curtir, cutucar online.}

Vol. 01, N. 04, Out. - Dez., 2018 - www.revistas.unilab.edu.br/index.php/rebeh 
Pegação é um termo dado pela comunidade gay aos encontros para sexo casual. Atualmente é comum que esses encontros sejam marcados por meios de aplicativos (apps) da internet como ressaltam Costa e Silva Júnior (2015, p. 6).

A construção desses espaços se mostrou para além das ruas um território útil para o encontro do público gay, uma vez que mesmo havendo exposições de ideias e práticas, também se configura como sendo um ambiente mais seguro (no que tange a violência física), específico e demarcador das práticas de tal público.

Com a internet os sujeitos passaram a estabelecer um tipo de relação que transgridem as noções de tempo e espaço, e ultrapassa os limites da sexualidade e do gênero. Nessas relações as identidades podem ser mantidas no anonimato, no "sigilo", o que possibilita uma experiência ainda mais diversificada e libidinosa.

Neste contexto, alguns termos tornaram-se bastante usuais nas redes sociais virtuais, tais como "convidar", "tc", "curtir", “cutucar", pois eles eram utilizados como forma de iniciar um contato entre interessados em uma pegação. Era comum convidar um amigo para o velho Orkut, teclar nas antigas salas bate-papo ou por $S M S$ do celular, ainda sem teclados digitais, curtir fotos ou cutucar alguém no Facebook, agora tudo isso migrou para os app.

O Bate-Papo da UOL está disponível aos seus usuários desde 1996. Naquele ano a internet era acessada por meio de um discador barulhento e CDs de operadoras. "Pedir para "teclar" (ou "tc", para os mais descolados) com alguém era o suficiente para engatar uma conversa com qualquer pessoa, sem saber se ela era ou não quem de fato dizia ser".

As estatísticas chegaram a computar numa página de Bate-Papo mais de 60 mil pessoas numa tarde, e segundo a UOL, no final da década de 1990 eram cerca de 30 mil participantes simultaneamente, com picos de 1,5 milhão de visitas diárias.

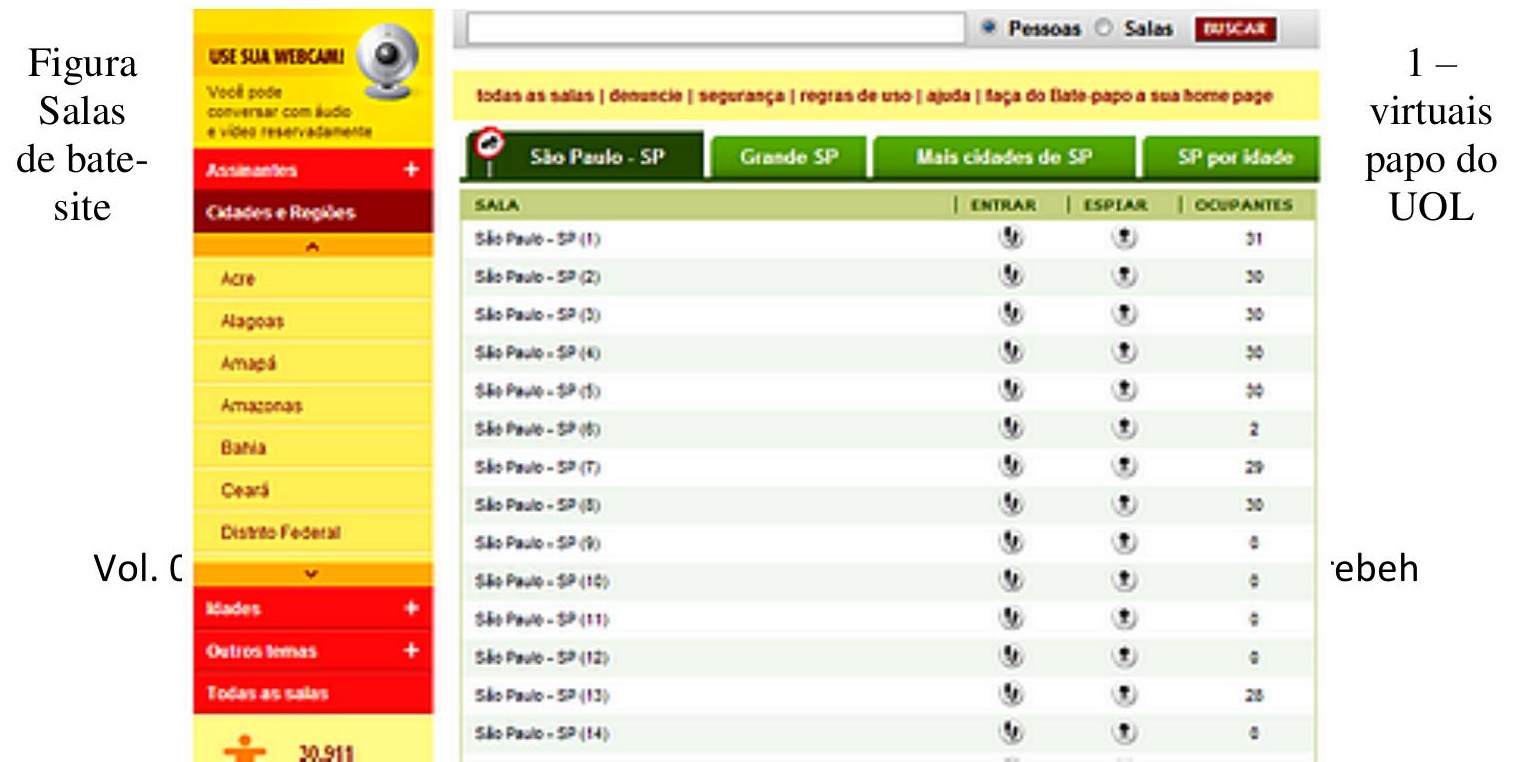


Podemos dizer que o Orkut foi uma das primeiras comunidades virtuais que possibilitaram a pegação. Planejado para ajudar seus membros a se relacionarem com outras pessoas por meio da rede, especialmente os norte-americanos, o Orkut teve como os maiores usuários a Índia e o Brasil, que chegou a registrar mais de 30 milhões de membros. Esse quantitativo de usuários era tão expressivo que a Google, que até então operava o Orkut na Califórnia, passou a operá-lo por meio da Google Brasil. O Orkut chegou a possuir $50 \%$ de usuários no Brasil, uma plataforma de relacionamento que foi encerrada em 2014 e que orkutizou desde 2004.

Um artifício muito usado para participar das comunidades gay ou para fazer pegação na rede, eram os nickname (apelido), uma vez que esses perfis possibilitavam que tais usuários fizessem contatos de nick para nick com risco menor de sofrerem insultos, serem desprezados, ignorados, rejeitados ou deletados e muitas vezes homem com perfil de mulher.

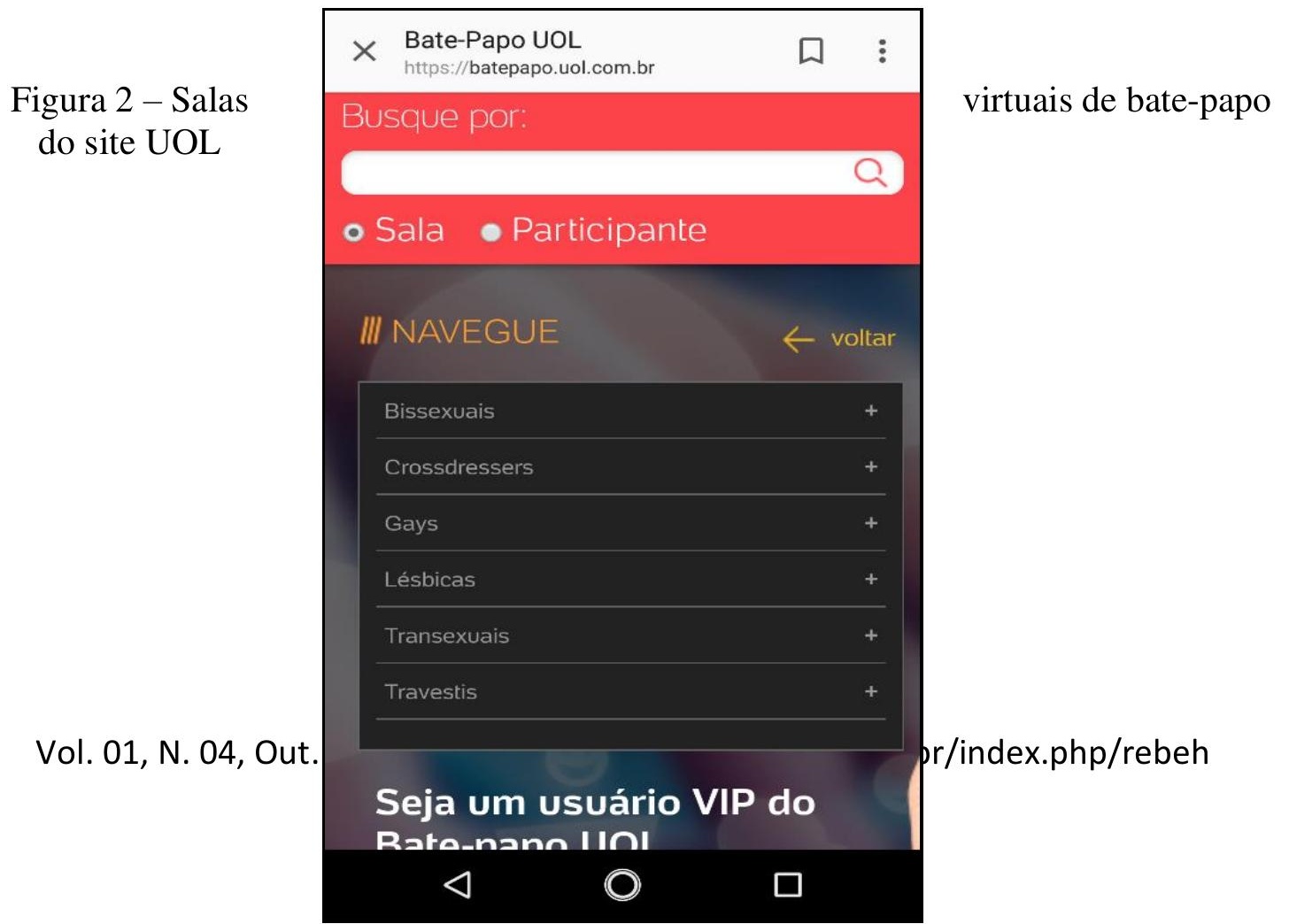


Fonte: UOL, 2018

Ao mesmo tempo que o Orkut, as salas de bate papo, daquele momento, tornaram-se espaços propícios de sociabilidade gay com conversas picantes, deram início ao que pôde vir a ser um encontro para sexo casual. Nas salas os usuários com seus nick geralmente fake podiam garantir o anonimato e o "sigilo" da pegação.

Desde 2012 o Facebook tornou-se a maior rede online do mundo chegando a ultrapassar 1.060 milhões de usuários mensais ativos, mas este não se tornou uma rede social tão quanto gayficado como as salas de bate papo e os aplicativos.

\section{App: dar like, dar match, mandar nudes para o crush}

O sentido original de crush é “queda”, “paixonite”, “paixão”, “desejo”. Diz-se do desejo (amor, atração, paixão) instantâneo por uma pessoa. Pelo menos é esse sentido que jovens internautas dão ao termo.

Cadastrar-se em um dos muitos os apps direcionado a relacionamento gays é algo muito simples, basta somente preencher alguns campos e pronto, o usuário já pode lançar-se em busca de outro, como escreveu Rocha (2016, p. 3):

\footnotetext{
Há vários aplicativos para encontrar pares de sexo casual entre amigos nas redes sociais. Através de um aparelho móvel, o GPS de um APP com 311 milhões de usuários, mostra a sua localização, mostra as pessoas que estão perto de si, se te adicionou como favorita, as pessoas com quem se cruzou na vida real, enfim, pode-se acessar literalmente o favorito.
}

Geralmente os usuários têm seus perfis publicados em vários apps, especialmente aqueles mais conhecidos e acessados no Brasil, como Grindr, Scruff, Tinder, outros também disponíveis são o Manhunt, Badoo, Bender. Todos são uma forma rápida e fácil de conhecer outros gays para pegação e/ou para um relacionamento.

Figura 3 - Perfil de usuário de aplicativo Scruff Vol. 01, N. 04, Out. - Dez., 2018 - www.revistas.unilab.edu.br/index.php/rebeh 


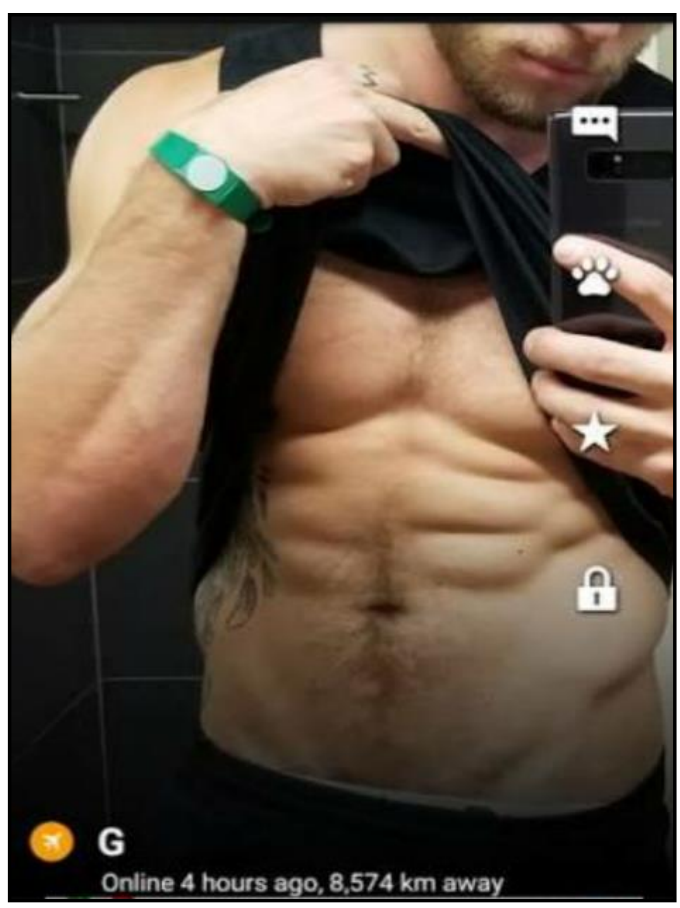

Fonte: Imagem de

domínio público, 2018.

Notadamente são duas as possibilidades de abordagens encontradas nestes apps, uma, a das pessoas com interesse em relacionamentos mais duradouros e outra, a das pessoas que buscam o fast fod ${ }^{3}$. É certo que, conforme Miskolci (2015, p. 75)

\begin{abstract}
A centralidade da busca do sexo sem compromisso revela-se um a priori que faz com que os usuários, até mesmo sem perceber, adentrem nesses espaços seguindo suas premissas. Um dos elementos mais evidentes está no design das plataformas e aplicativos dirigidos a esse público, o qual valoriza a imagem em detrimento da escrita.
\end{abstract}

Uma nuance dos perfis constantes nesses apps é que não é difícil encontrar descrições de gays que se colocam como não afeminados, discretos e de fora do meio, que buscam por parceiros, também, não afeminado, que sejam sigilosos e de fora do meio. Tal descrição nos possibilita perceber uma desqualificação do meio gay, em que determinados gays que rechaçam o corpo feminil e pintoso de outros gays (ROCHA, 2016).

Costa e Silva Júnior (2015) apontam que a mídia tem trazido uma linguagem que adota termos que são próprios do público LGBTQI+, criando neologismos e subvertendo

\footnotetext{
${ }^{3}$ No Brasil, e especificamente em meu campo paulistano, o fast foda denomina negativamente o sexo sem compromisso compreendido como sinal de promiscuidade. Entre homens que buscam por outros homens, essa forma de busca de parceiros e se relacionar sexualmente evoca em muitos uma possível continuidade do antigo cruising gay, algo que aqui foi mais conhecido como "pegação" em locais públicos como parques, banheiros e estacionamentos (MISKOLCI, 2015, p. 77).
}

Vol. 01, N. 04, Out. - Dez., 2018 - www.revistas.unilab.edu.br/index.php/rebeh 
palavras, construindo com isso um dicionário irreverente e específico que contribuem para a promoção de uma cultura gay disseminada por meio da internet, especialmente por meio das redes sociais.

Atualmente o Grindr é o aplicativo de encontros gay mais conhecido do mundo. É uma rede geossocial que pode ser usada no Android, iPhone, iPod Touch, iPad e Blackberry OS. Disponível para download a partir da App Store e o Android Market/Play Store. O Grindr vem em duas versões livres e o baseado em assinatura (Grindr Xtra). O aplicativo faz uso do dispositivo geolocalização, que permite aos usuários acessar outros gays e homens bissexuais em estreita proximidade.

Figura $4-$ Crush gay

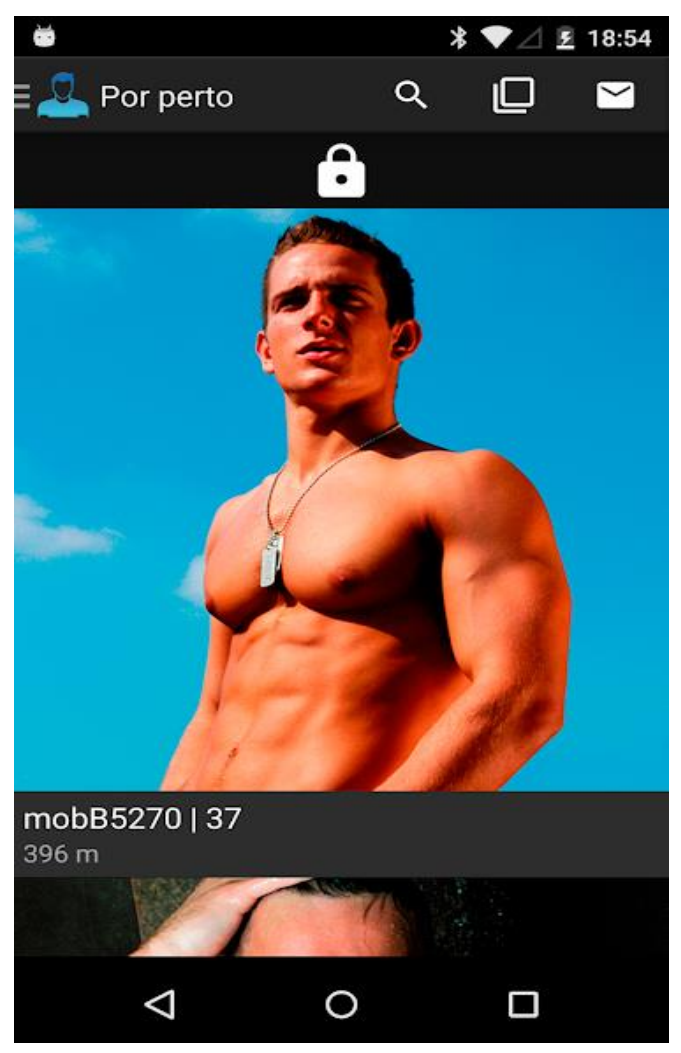

Fonte: Google Play Store, 2018

Em maio de 2011, o Brasil detinha 14.044 usuários do Grindr e em 2018 passou a ter uma nova funcionalidade que pretendeu deixar as conversas entre os usuários mais próximas, através de um mecanismo de mensagens de voz, um mesmo formato como acontece com os clipes de áudio enviados no WhatsApp.

Figura 5 - Grindr: Chat, encontro e namoro gay

Vol. 01, N. 04, Out. - Dez., 2018 - www.revistas.unilab.edu.br/index.php/rebeh 


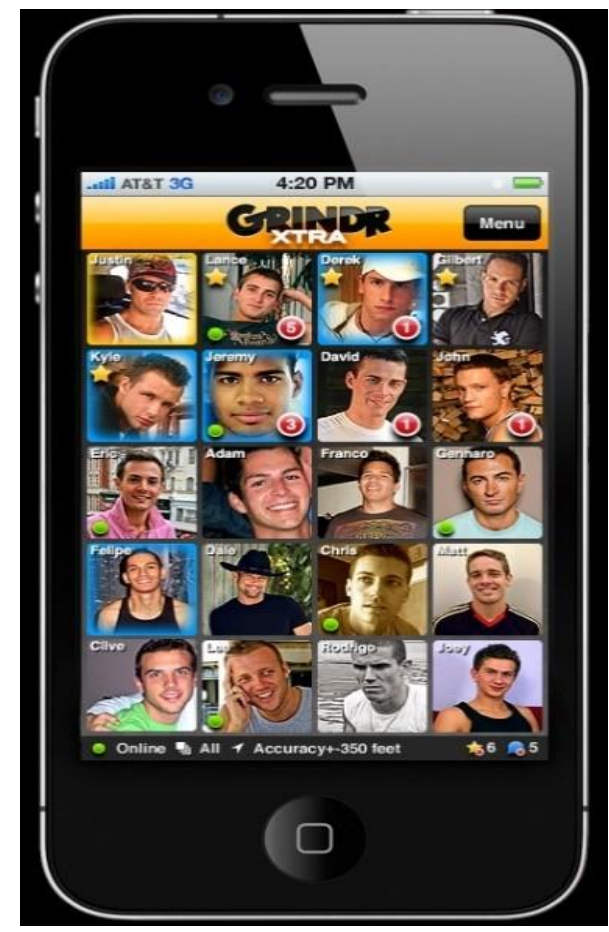

Fonte: Meio Bit, 2018

Esse app é considerado o melhor aplicativo social móvel grátis para gays, bi, trans e homossexuais se encontrarem. Possui mais de 3 milhões de usuários em todo mundo em 192 países. Seu anúncio chama a atenção para: “converse e encontre com pessoas interessantes de graça, ou faça upgrade para o Grindr XTRA para ter mais recursos, diversão e chances de conectar", todavia as demais funcionalidades do app são pagas.

$\mathrm{Na}$ pesquisa de 2017 do site Guia Gay São Paulo (Disponível em: <http://www.guiagaysaopaulo.com.br>), somente $22 \%$ analisam se crush é ativo ou passivo nos aplicativos. Nessa pesquisa realizada com 4.800 pessoas (héteros, bis, homos), foram analisados o perfil dos solteiros brasileiros e seu comportamento diante de um relacionamento.

Os dados revelaram que "a maioria dos solteiros (71\%) não tem vergonha e nem preconceito sobre o uso dos aplicativos de relacionamento". Em relação o que faz com que gays iniciem um papo nos aplicativos: " $81 \%$ disseram que priorizam os que buscam as mesmas coisas que eles"; "55\% preferem conversas com que tem fotos nítidas de rostos", "22\% analisam se a preferência na cama, ativo - passivo, é compatível com a sua". Se o aplicativo é somente para sexo, eles responderam: "para 50\% a intenção é conhecer pessoas para sair e se divertir".

Vol. 01, N. 04, Out. - Dez., 2018 - www.revistas.unilab.edu.br/index.php/rebeh 
Desde 2015, o Brasil com uma população de 204 milhões de brasileiros, conta com 78 milhões, desses, (quase 40\%) que acessam as redes sociais direto de seus smartphones.

Estamos vivendo a fase dos aplicativos, que tem tornada a vida social muito mais simples em todos as necessidades de comunicação e interação. Existem milhares de aplicativos para todos os tipos de interesses, necessidades e finalidades.

Um aplicativo pode conectar pessoas, pode garantir diversão e sociabilidade a qualquer momento e em quaisquer locais.

Os aplicativos, nos parecem, um território que tem se tornado cada vez mais utilizados pelas pessoas LGBTQI+ para melhor conectarem uma conquista e exercerem a orientação de seu prazer ou não.

\section{À guisa de conclusão}

Privacidade termo polifônico em que uma de suas explicações pode ser controle e guarda de proteção da vida privada. Todavia, este conceito se amplia, e ao se considerar, que não está associada apenas a função de esconder alguma informação, mas também significando o direito de escolha entre o que deseja ou não ser exposto. $\mathrm{O}$ debate sobre a privacidade chegou à judicialização do direito da privacidade eletrônica em função do grande número de casos de invasão de privacidade.

No Brasil o Marco Civil da Internet define que o acesso à internet é essencial ao exercício da cidadania e ao usuário são assegurados direitos à inviolabilidade e ao sigilo de suas comunicações pela internet, salvo por ordem judicial, nas hipóteses e na forma que a lei estabelecer, para fins de investigação criminal ou instrução processual penal (BRASIL, 2014).

Portanto há uma regulamentação de garantia de direitos ao assegurar que se tem direitos à privacidade e à liberdade de expressão nas comunicações como uma condição para o pleno exercício do direito de acesso à internet.

Recentemente juízes tem suspendido o funcionamento do app WhatsApp por ordem judicial. Todavia, o WhatsApp é um dispositivo de comunicação e o acesso a estas só poderia ser autorizado mediante ordem judicial. Para que se defira a quebra de sigilo das comunicações realizadas no aplicativo é necessário judicializar.

Vol. 01, N. 04, Out. - Dez., 2018 - www.revistas.unilab.edu.br/index.php/rebeh 
Pois bem, sigilo, é o que deve ou deveria permanecer escondido da vista ou do conhecimento de outrem; segredo, caracterizado como coisa ou fato que não se pode revelar ou divulgar.

Como se conectar em um aplicativo e querer sigilo de sua orientação sexual ou de seu desejo sexual? É uma das questões que nos instigam nesse trabalho de sociabilidade gay.

Uma das questões que revelam o uso sigiloso dos app, "são dos usuários em locais em que a homossexualidade é crime, como o Irã. E outras em que é visto com outros olhos, como Afeganistão, Etiópia, Haiti, Iraque, Ruanda, Sri Lanka e Yemen”, dizem os analistas. "No total em todos os países, são cerca de 8 mil novos usuários por dia".

Existem outras opções de app como o Scruff, Manhunt, Bender e outros para opções gays específicas: o u4Bear, app exclusivo para homens que são ou procuram o tipo "urso".

Os aplicativos no geral apresentam-se com uma grade de imagens, ou sem imagens de perfis, exibindo geralmente os corpos disponíveis. No aplicativo é possível acessar se o possível crush está online, sua distância, idade, peso, altura, se ele se entende negro, latino, asiático, árabe. Portanto, a maioria dessas informações pode não ser obrigatoriamente respondidas ou estarem em sigilo.

Nos app pode-se bloquear pessoas ou até denunciá-las, o que nos sinaliza que o "fast foda" e a "identidade sexual mediada", mesmo no pseudo sigilo, ainda não estão desterritorializadas e livres de preconceitos e homofobia inclusive virtual.

\section{Referências}

BRASIL. Lei n ${ }^{\circ} 12.965$, de 23 de abril de 2014. Estabelece princípios, garantias, direitos e deveres para o uso da Internet no Brasil. Disponível em: <http://www.planalto.gov.br/ccivil_03/_ato2011-2014/2014/lei/112965.htm> Acesso em: 19 jun. 2018.

COSTA, Milane do Nascimento; SILVA JÚNIOR, Claudio Gomes. "Que Bicha É Essa?" uma análise da cultura gay na internet: comportamentos, subjetividades e linguagens. In: Anais do V Reunião Equatorial de Antropologia, XIV Reunião de Antropólogos do Norte e Nordeste, Maceió: UFAL, p. 1-13, 2015.

Vol. 01, N. 04, Out. - Dez., 2018 - www.revistas.unilab.edu.br/index.php/rebeh 
CHRISTAKIS, Nicholas A; FOWLER, James H. O poder das conexões: a importância do networking e como ele molda nossas vidas. Rio de Janeiro: Elsevier, 2010.

FRANCO, I. Redes sociais e a ead. In: FREDRIC, M; FOMIGA, M. (Orgs.) Educação a distância: o estado da arte. São Paulo: Pearson, 2012.

HINE, Christine. Etnografía virtual. Colección nuevas tecnologias y sociedade. Barcelona: UOC, 2004.

LORENZO, Eder Maria. A utilização das redes sociais na educação. 3. ed. Rio de Janeiro: Clube de Autores, 2013.

LOURO, Guacira Lopes. Pedagogias da sexualidade. In: LOURO, Guacira Lopes. (Org). O corpo educado: pedagogia da sexualidade. Traduação Tomás Tadeu da Silva. 3. ed. 2. reimp. Belo Horizonte: Autênntica, p. 7-34, 2016.

MISKOLCI, Richard. "Discreto e fora do meio": notas sobre a visibilidade sexual contemporânea. In: Cadernos Pagu (44), p. 61-90, jan.-jun. 2015. Disponível em: <http://www.scielo.br> Acesso em: 19 jun. 2018.

ROCHA, Damião. No corpo whey protein de falsos heteros as gays "barbies" rechaçam o corpo feminil das gays "pintosas" passivas. In: Artefactum, ano VIII, $n$. 02, p. 1-13, 2016.

VERMELHO, Sônia Cristina. et al. Refletindo sobre as redes sociais digitais. In: Educação e Sociedade, Campinas, v. 35, n. 126, jan. a mar., p. 179-196, 2014. Disponível em <http://www.cedes.unicamp.br> Acesso em: 7 fev. 2017.

\title{
SEND NUDES: \\ THE GAY CRUSHES IN THE FAST FUCK APPLICATIONS OF RELATIONSHIPS
}

\begin{abstract}
With ranking of the degree of catching and with greater chance of sex, the applications are multiplying and bombing in the online social network. One of these applications comes with a call-type: If you're a kid looking for boys, this is your application. With it you can see other people close to you and if they like boys, boys and girls or just want to know how the whole thing works. The text is the result of the research we have been doing in the Graduate Program in Education of the Federal University of Tocantins (PPGE / UFT) in the last five years and portrays the interactions of LGBTQI + people in online networks, virtual communities or applications. It is a qualitative research, descriptive and analytical, from the perspective of Netnopesquisa. Vol. 01, N. 04, Out. - Dez., 2018 - www.revistas.unilab.edu.br/index.php/rebeh
\end{abstract}


Among other aspects the application shows how many meters away each person is from you and has the option of instant chat and sending photos. And as the app is not necessarily integrated with Facebook or another social network, you can ensure your anonymity. What these applications promote from interactions and tastes are the important issues to think about gay sociability on the world computer network and crush as passion soaring, fast and ephemeral.

Keywords: App; Sociability of LGBTQI + people; Interactions and fun.

Recebido em: 14/08/18

Aprovado em:12/01/19 